Vol.59: e16150508, January-December 2016 http://dx.doi.org/10.1590/1678-4324-2016150508

ISSN 1678-4324 Online Edition
BRAZILIAN ARCHIVES OF BIOLOGY AND TECHNOLOGY

AN INTERNATIONAL JOURNAL

\title{
Comparative Microbicidal Efficacy of Fractionated Extracts from In Vitro and In Vivo Raised Cells of Tinosporacordifolia Against MDR Pathogens
}

\author{
Jitendra Mittal $^{1}$; Abhijeet Singh ${ }^{1}$; Amla Batra ${ }^{2}$; Madan Mohan Sharma ${ }^{1}$ * \\ ${ }^{1}$ Department of Biosciences, Manipal University Jaipur,VPODehmikalan, Jaipur Ajmer Expressway. \\ ${ }^{2}$ Department of Botany, University of Rajasthan Jaipur.
}

\begin{abstract}
The present study was conducted to explore the hidden potential of natural products synthesized in the medicinal plant Tinosporacordifolia. This plantis prioritized by National Medicinal Plant Board, New Delhi. Leaf and inter nodal segments were inoculated on MS Medium fortified with IBA (1.0 mg/L) produced callus after four weeks. The calli were brown due to phenolic substance secreted by the explant. This problem was overcome by using adjuvant PVP (0.1\%). Further, secondary metabolites were isolated from callus and field leaf through soxhlet extractor and fractionated by using column chromatography. The antibacterial activity of these fractioned extracts from Tinosporacordifolia callus and leaf were seen against multi drug resistance bacteria viz., Escherichia coli (ATCC 25922), Pseudomonas aeruginosa, (ATCC 27853) \& Staphylococcus aureus (ATCC 29213) and against plant pathogenic fungus Fuseriumoxisporum(MTCC 8608) and Sclerotiniasclerotiorum (MTCC 8785). All fractionated extracts showed antimicrobial activity but callus extracts were proved to be best in compare to leaf extracts. Furthermore, we are trying to analyze different bio active compounds through GCMS.
\end{abstract}

Key words: Medicinal plants, callus, natural products, PVP, Antimicrobial activity

*Author for correspondence: madanmohan.sharma@jaipur.manipal.edu 


\section{INTRODUCTION}

Plant cells are factories of natural compounds which are used to produce drug to cure a number of aliments from prehistoric time as ethno medicines. These natural products have also been using in pharmaceuticals, agrochemicals, ingredients of flavors and fragrances, food additives and pesticides (Sharma et al. 2010). The natural habitats for medicinal plants are vanishing at a faster rate due to developmental activities of nation. Hence, it has become difficult to acquire natural compounds from the phytodiversity. Even though, pharmacological industries have produced a number of new synthetic antibiotics in the last few decades, but resistance to these drugs has increased in microorganisms (Wright 2010). This has encouraged industries, as well as scientists to consider the possibilities of investigation of cell cultures as an alternative supply for the production of plant pharmaceuticals (Yue et al. 2014).

In the search for alternative to produce desirable medicinal compounds from plants, biotechnological approaches especially plant tissue culture technology is found to have potential applications over traditional agriculture practices for the industrial production of bioactive plant metabolites (Barbulova et al. 2014).

Some of these natural products have been produced through callus culture usingPhyllanthusamarus (Sen et al. 2009), Verbesinaencelioides (Karnawat et al. 2010) and Polygonummultiflorum (Zhou et al. 2011). The possible applications of plant cell cultures for the specific biotransformation of natural compounds have been reported (Sharma et al. 2012; Barbulova et al. 2014). Due to these advances, research in the area of tissue culture technology for the production of bioactive compounds has gained popularity beyond expectations.

Keeping in view the high demand of these bioactive compounds for commercial production of drugs, efforts have been made to utilize a medicinally potent plant Tinosporacordifolia(Willd.) Miersex Hook. F. and Thoms (family Menispermaceae) to analyze its therapeutic values against the microbes which have high resistance against the existing drugs. It is a large, deciduous, climbing shrub found throughout India, especially in the tropical parts ascending to an altitude of $300 \mathrm{~m}$. and also in certain parts of China (Anonymous 1976). It is rich with a variety of natural chemical constituents (Berberine, Tinosporin, Cordifolioside) (Patel et al. 2011; Sangeethaa et al. 2013). These natural products have been used to cure a number of ailments like viral infections, cancer, diabetes, inflammation, immunomodulatory activity, neurological, psychiatric conditions, vasorelaxant, inflammation, microbial infection, hypertension, HIV etc. (Patel et al. 2009; Upadhyay et al. 2011; Nagarkar et al. 2013; Joladarash et al. 2014; Mittal et al. 2014).

This plant species has a huge variety of bioactive compounds; hence, it requires scientific attention for its conservation to continuous supply of these bioactive compounds. To fulfill the present day needs, callus culture is the alternative method to conserve and enhance the production of secondary metabolites under laboratory conditions. Therefore, the present investigation was carried out with the objectives to provide new vistas on the cell culture to elucidate the effect of plant growth regulators on callus cultures and role of different adjuvants to overcome leaching of phenolic substances. Isolation and fractionation of secondary metabolites of in vivo plant leaf and callus has been done. Antimicrobial efficacy of both the purified extracts in their fractions has evaluated against different pathogenic bacteria and plant pathogenic fungus by disc diffusion method and food poisoning method respectively. Serial dilution turbidity measurement assay has been also carried out to calculate minimum inhibitory concentration (MIC).

\section{MATERIAL AND METHODS}

\section{Explant preparation:}

Fresh twigs were collected from one year old plant and cut into $1.0-1.5 \mathrm{~cm}$ long intermodal segments and leaf segments $\left(1.0 \mathrm{~cm}^{2}\right)$ for callus production. These explants were surface sterilized under running tap water to remove soil particles and other surface debris on plants followed by washing with $0.5 \%$ Tween 20 (1-2 minutes) for removal of surface contaminants. Subsequently, explants were subjected to 
surface sterilization in laminar air flow by successively dipping in $70 \%$ ethanol for $1 \mathrm{~min}$ and $0.1 \%$ mercuric chloride for $1 \mathrm{~min}$. Finally, the sterilized explants were rinsed with autoclaved distilled water for three times under aseptic conditions and used for inoculation.

\section{Nutrient Medium and Hormone:}

Murashige and Skoog (MS) Medium with different concentrations of auxin such as IBA, IAA, NAA, 2,4-D $(0.5-5.0 \mathrm{mg} / \mathrm{L})$ and cytokinin viz., BAP, Kinetin, TDZ, $2 \mathrm{iP}$ (0.5$5.0 \mathrm{mg} / \mathrm{L}$ ) were used for callus production. The MS medium consisted of 95\% water, macro and micronutrients, vitamins, amino acids, sugars. Besides, MS medium contained sucrose $(3.0 \%)$ as a carbon source and agar powder $(0.8 \%)$ as a gelling agent to make this medium semisolid.

\section{Inoculation and culture of explants:}

Surface sterilized explants were inoculated on MS medium fortified with various auxin viz. IBA, IAA, NAA, 2,4-D (0.5-5.0 mg/L) and cytokinin such as BAP, Kn, TDZ, 2iP (0.5-5.0 $\mathrm{mg} / \mathrm{l})$ for callus production. The culture vials were incubated at $25^{0} \pm 2^{0} \mathrm{C}$ temperature under $16 \mathrm{~h}$ photoperiod with cool, white fluorescent lights (Philips India Ltd, Mumbai) of $25 \mu \mathrm{mol}$ $\mathrm{m}^{-2} \mathrm{~s}^{-1}$ light intensity and $8 \mathrm{hrs}$. dark cycle with $55 \pm 5 \%$ relative humidity. All experiments were set with eight replicates and repeated at least thrice. All cultures were observed daily for the observation of gradual changes. Morphological changes were documented with the photographs and recorded. All data were subjected to statistical methods.

\section{Experiment to overcome leaching:}

After 15-18 days of inoculation green callus was produced but after 3-4 days it turns brown to black due to secretion of phenolic substances and stop further growth of callus. To overcome these problem explants were socked in DI water for 2 hrs. Subsequently these explants were socked in a mixture of activated charcoal, PVP, ascorbic acid and citric acid (1\%: $0.1 \%$ : $0.05 \%$ : $0.05 \%$ ) for 30 , 45, $60 \mathrm{~min}$. Finally these explants were washed with autoclaved distilled water and go through surface sterilization under laminar air flow. For reduction of leaching MS medium was also fortified with different adjuvants viz., activated charcoal (0.1-5.0\%), PVP (0.1$1.0 \%)$, Ascorbic Acid (0.01-0.5\%), Citric Acid (0.01-0.5\%) alone and in combination also.

\section{Isolation of secondary metabolites:}

Fresh leaves were collected and washed under running tap water to remove adhering soil particles. The leaves and 4 weeks old callus induced from inter nodal explants were dried at room temperature for one week to make it coarse powdered and stored in an air tight container. $20 \mathrm{~g}$ of powdered samples of leaves and callus was extracted with methanol at $50^{\circ} \mathrm{C}$ temperature in soxhlet extractor apparatus (Borosil, India) of $72 \mathrm{~h}$. The collected extracts were concentrated using a rotary evaporator to get a viscous mass at $45^{\circ} \mathrm{C}$. The viscous masses were fractionated with different solvents using column chromatography. 2 gram dry extract was subjected to a silica gel-60 column chromatography and eluted with petroleum ether $(100 \%)$, petroleum ether: chloroform $(80: 20, \quad 60: 40, \quad 40: 60, \quad 20: 80)$, chloroform (100\%), chloroform: ethyl acetate (80:20, $60: 40,40: 60,20: 80)$, ethyl acetate (100\%), ethyl acetate: methanol (80:20, 60:40, 40:60, 20:80) and methanol (100\%). All fractions were filtered using syringe filter $(0.22 \mu \mathrm{m})$ and concentrated to dryness under reduced pressure below $60^{\circ}$ using a rotary flash evaporator (Heidolph, India) for further analysis.

\section{Antimicrobial assay:}

All fractionated extracts were dissolved in DMSO (Dimethyl Sulphoxide) to give a final concentration of $100 \mathrm{mg} / \mathrm{mL}$ each. Three different bacterial strains Escherichia coli ATCC 25922, Pseudomonas aeruginosa ATCC 27853 and Staphylococcus aureus ATCC 29213 were used for antibacterial activity and two plant pathogenic fungus Fusarium oxisporum MTCC 8608 and SclerotiniasclerotiorumMTCC 8785 were used for antifungal activity.

Minimum inhibitory concentration (MIC) of fractionated extracts were evaluated against bacteria and fungus by serial dilution turbidity measurement assay. For serial dilution turbidity measurement assay, nutrients broths 
were prepared and distributed in several culture tubes. Each tube contains $10 \mathrm{~mL}$ of nutrient broth. The stock solution of isolated fractions was serially diluted at $10^{-1}, 10^{-2}$ and $10^{-3}$ level. The tubes were inoculated with 50 $\mu \mathrm{L}$ of $24 \mathrm{~h}$ old bacterial suspension. Each tube was mixed with $0.1 \mathrm{~mL}$ of plant extract fractions of different concentration. The tubes were incubated for $24 \mathrm{~h}$ at $37^{\circ} \mathrm{C}$ and OD was taken at $600 \mathrm{~nm}$ by using spectrophotometer (Systronics, India) to measure the turbidity against a sterile blank. A negative control without bacterium and a positive control without plant extract were incubated for comparative purpose. All the experiments were done in triplicate.

Antibacterial activities were carried out by agar disc diffusion method. The nutrient agar plates were used for culture of all bacterial strains and for evaluating antibacterial activity. The bacterial suspension was spread equally on the nutrient agar plates using sterilized spreader. The sterile Whatman No 1 paper disc at $6 \mathrm{~mm}$ diameter was soaked in different fractionated extracts at minimum inhibitory concentrations evaluated by previous experiment. The disc without any solution, placed on the plates was act as control. These NA plates were incubated in for $24 \mathrm{~h}$ at $37{ }^{\circ} \mathrm{C}$. However, the susceptibility of the test organism was determined by measuring the diameter of the zone of inhibition (ZOI) and all data were statistically analyzed.

Antifungal efficacy was also analyzed by the standard food poisoning method. Different fractions of secondary metabolites were mixed in Potato Dextrose Agar (PDA) medium. The fungal strain was inoculated by point inoculation method with the help of sterile needle. PDA plate without plant extract was maintained as control. These plates are incubated in inverted position for $72 \mathrm{~h}$. at $27 \circ$ C. Each experiment was carried out in triplicate and diameter of the zone of inhibition was measured and all data were statistically analyzed.

\section{RESULT AND DISCUSSION}

Callus initiation was observed on inter nodal segments inoculated on basal MS medium supplemented with various auxins either alone or in combination such as IBA, IAA, NAA, 2,4-D. Optimum results were observed when
IBA alone was used with MS medium in different concentration $(0.5,1,1.5,2.5$ and $5.0 \mathrm{mg} / \mathrm{L})$. The highest biomass of callus was obtained on IBA $(1.0 \mathrm{mg} / \mathrm{L})$. The proliferation efficiency of through inter nodal segments was significantly higher when compared with leaf explants within three to four weeks. Swelling of inter nodal segments was followed by callus initiation within one week of inoculation (Fig.1A). Further, cells simultaneously absorb nutrients from the medium and callus proliferation was obtained on MS medium augmented with IBA $(1.0 \mathrm{mg} / \mathrm{L})$. Callus was pale green, spongy, and fragile in nature (Fig. $1 \mathrm{~B}$ and $1 \mathrm{C})$. In consonance to our results of callus production, Gururaj et al. (2007) also reported callus production on MS medium supplemented with IBA (1.0 mg/L) and 2ip $(0.5-1.0 \mathrm{mg} / \mathrm{L})$ via nodal segments explant of T. cordifolia. However, in contrast to our findings, Rao et al. (2008) shoed initiation of callus on MS medium fortified with NAA (4.0 $\mathrm{mg} / \mathrm{L})$ using leaf explant of $T$. cordifolia.

The callus changed its colour from brown to black after three weeks (Fig. 1D). This is mainly due to the secretion of phenolic compounds in the medium, which prohibited further growth of callus. Different adjuvants were tested to overcome this leaching issue, out of them PVP $(0.1 \%)$ proved to be the best in leaching control (Fig. 1E and F).

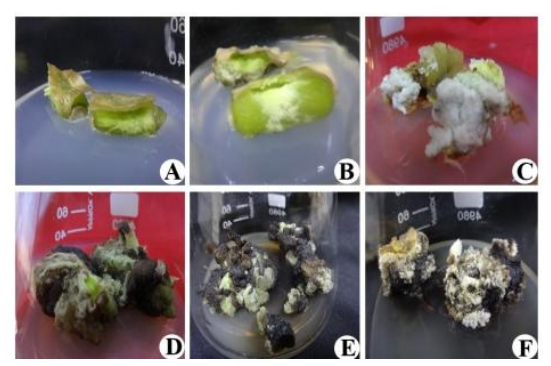

Figure 1-Differentstagesofcallusproduction via inter nodal segments cultured on MS medium supplemented with IBA (1.0mg/L)

A: In vitro callus initiation after one week

B: Further growth of callus after two weeks

C: Growth of callus after sub culturing on the same medium

D: Browning of callus duet secretion of phenolic substances

E: Brown callus trea ted with PVP $(0.1 \%)$

F:Greeningofcallustreatedwith PVP $(0.1 \%)$

Subsequently, the callus was sub cultured after every two weeks on MS medium supplemented with IBA $(1.0 \mathrm{mg} / \mathrm{L})$ and PVP $(0.1 \%)$. 
Similarly, browning of medium and explants has been observed in Dioscoreahispidaand Dioscoreapentaphylla (Shukla and Shukla, 2014). Sivakumar et al. (2014) also studied effect of four types of antioxidants and adjuvants on the control of explant and culture medium oxidation during in vitro cultivation of $T$. cordifolia.

Furthermore, secondary metabolites were also isolated from in vivo leaf and in vitro callus and purified by column chromatography for testing its antimicrobial efficacy. Total six fractions FC1, FC2, FC3, FC4, FC5 and FC6 were finally obtained from callus while six fractionsFL1, FL2, FL3, FL4, FL5 and FL6 were obtained from leaf sample. All the fractions were assayed for testing its antimicrobial efficacy against three pathogenic bacterial strains and two plant pathogenic fungi.

In order to determine MIC, serial dilution turbidity measurement assay was carried out with a series of different concentration of extracted fractions of callus and leaf. The results of serial dilution method are illustrated in Table 1. The fractionated extracts when added to the liquid medium, start their antimicrobial activities in terms of inhibition of the growth of microbes. This inhibition is measured in terms of optical density values (OD). The MIC value indicates that the fractioned extract of leaf and callus of $T$. cordifolia inhibit the growth of test organisms at different concentrations (30-50 ppm). The results of MIC assays showed that the antimicrobial activities of extracted fractions of callus (FC1-FC6) are as effective as extracted fractions of leaf (FL1-FL6) against different microbial strains tested. This is possibly due to the higher concentration of secondary metabolites in callus than leaf (Jain et al. 2012). The similar studies were also carried out using Rhuscoriaria L. (VahidDastjerdi et al. 2014), Hydnoraafricana(Wintolaet al. 2015) and Plantagolanceolata (Ferrazzano et al. 2015) plant extracts.

Table 1:Minimum inhibitory concentration $(\mu \mathrm{g} / \mathrm{mL})$ of fractionated extract of callus and leaf against different pathogenic bacteria and plant pathogenic fungus

\begin{tabular}{lrrrrrrrrrrrr}
\hline & & \multicolumn{1}{c}{ MIC in $\mu \mathrm{g} / \mathrm{ml}(\mathrm{PPM})$} & & & \\
MIC & FC1 & FL1 & FC2 & FL2 & FC3 & FL3 & FC4 & FL4 & FC5 & FL5 & FC6 & FL6 \\
Strain & & & & & & & & & & & & \\
E. coli & 30 & 40 & 35 & 40 & 25 & 30 & 30 & 40 & 35 & 50 & 25 & 40 \\
S. aureus & 40 & 50 & 35 & 40 & 30 & 40 & 35 & 35 & 30 & 40 & 30 & 35 \\
P. aeruginosa & 45 & 45 & 40 & 40 & 35 & 40 & 40 & 50 & 35 & 50 & 30 & 40 \\
S. sclerotiorum & 50 & 50 & 50 & 50 & 40 & 45 & 45 & 50 & 40 & 50 & 40 & 50 \\
F. oxisporum & 45 & 50 & 45 & 50 & 40 & 45 & 45 & 45 & 40 & 45 & 40 & 50 \\
\hline
\end{tabular}

All fractions of callus and leaf showed antibacterial as well as anti-fungal activity. The results of disc diffusion assays indicate that the fraction 3 of callus showed maximum ZOI against $E$. coli, while fraction 5 of callus showed maximum ZOI against S. aureus (Fig. $2 \mathrm{~A}$ and $\mathrm{B})$. For $P$. aeruginosa fraction 6 of callus proved to be the best (Fig. 2C). Plant pathogenic fungus $F$. oxisporum and $S$. sclerotiorumwere analyzed by food poisoning method (Fig. 2D and E). Fraction 3 of callus showed maximum ZOI against $F$. oxisporumandfraction 5 and 6 of callus were also showed significant ZOI against $F$. oxisporum, while fraction 6 showed maximum ZOI against $S$. sclerotiorum. Similarly to the MIC by serial dilution method, fractions of callus extracts showed better zone of inhibition (ZOI) by disc diffusion and food poisoning methods than fractions of leaf extracts. There are numerous reports in support to our findings (Srivastavaet al. 2013; Castilho et al. 2014; Kumariet al. 2015; de Souza et al. 2015). 


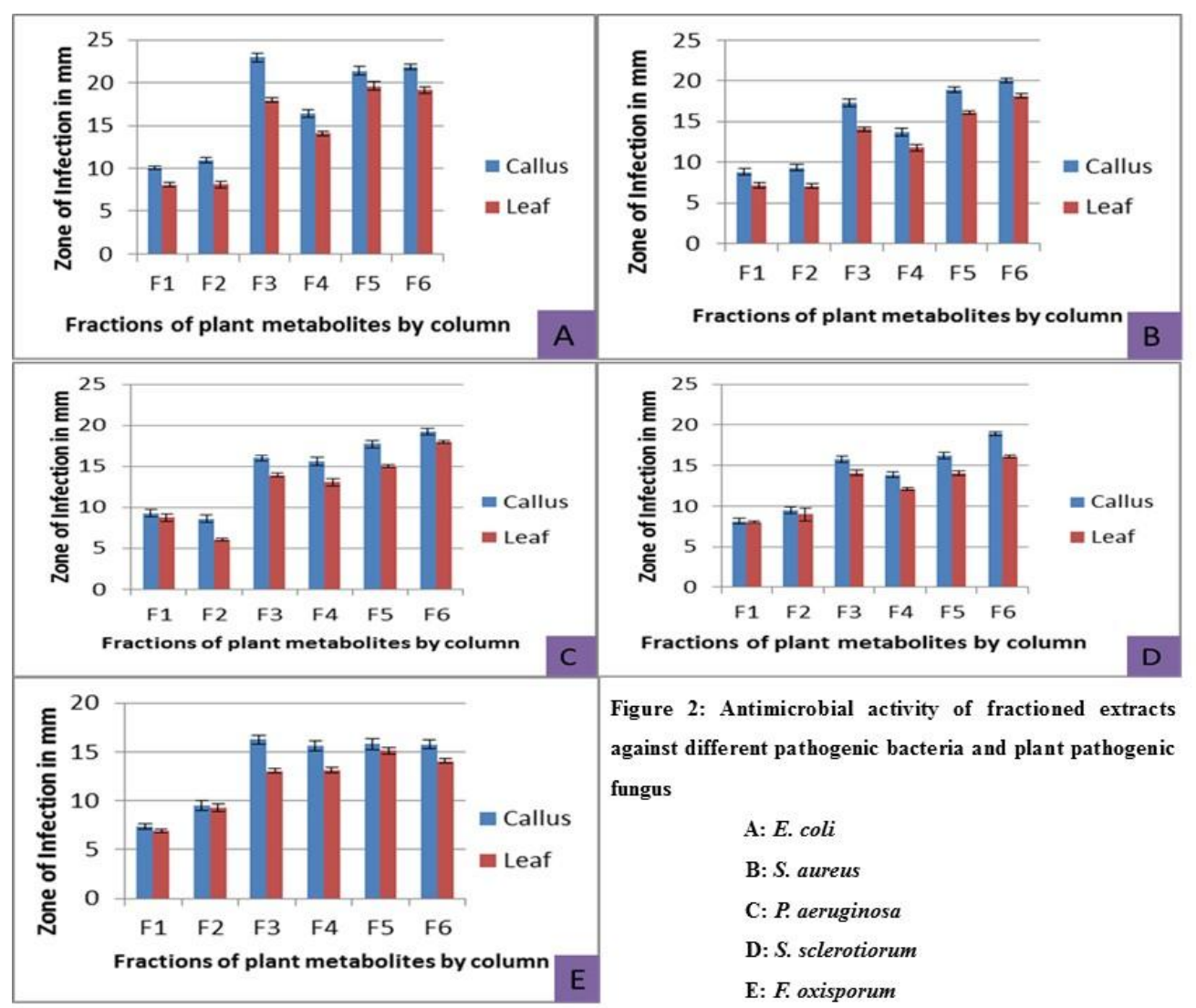

Figure 2- Antimicrobial activity of fractioned extracts against different pathogenic bacteria and plant pathogenic fungus

A: E. coli

B: S. aureus

C: P. aeruginosa

D: S. sclerotiorum

E: F. oxisporum

Several reports suggest that the in vitro shoot culture show maximum accumulation of bioactive compounds (Sharda et al. 2007; Jain et al. 2011). In the present study the callus culture showed maximum ZOI may be due to higher concentration of secondary metabolites in the extract than that of the extract obtained from field leaves. Plant cell cultures supplemented with auxins have tendency to increase the endogenous auxin levels in the callus and hence decrease the morphogenetic potential. This results in higher accumulation of bioactive compounds in the callus (Das et al. 2013).

\section{CONCLUSION}

The callus was produced from inter nodal segments of Tinosporacordifolia for regular supply of bioactive compounds. Secondary metabolites were isolated and fractionated by using column chromatography by in vitro produced callus as well as in vivo leaf samples. The antibacterial activity of these fractioned extracts from Tinosporacordifolia callus and leaf were seen against multi drug resistance bacteria and plant pathogenic fungus. All fractionated extracts showed antimicrobial activity but callus extracts were proved to be best in compare to leaf extracts. Further, we are trying to analyze different bio active compounds through GCMS.

\section{ACKNOWLEDGEMENT}

The authors are grateful to Prof. Sandeep Sancheti, President, Manipal University Jaipur for providing necessary infrastructural facilities to carry out this research work. 


\section{REFERENCES}

Anonymous. Wealth of India: Raw materials. CSIR, New Delhi, 10, 1976.

Barbulova A, Apone F, Colucci G. Plant Cell Cultures as Source of Cosmetic Active Ingredients. Cosmetics. 2014; 1:94-104.

Castilho AL, da Silva JPC, Saraceni CHC, Díaz IEC, Paciencia MLB, Varella AD, Suffredini IV. In vitro activity of Amazon plant extracts against Enterococcus faecalis. Braz J Microbiol. 2014; 45(3), 769-779.

Das J, Mao AA, Handique PJ. Callus-mediated organogenesis and effect of growth regulators on production of different valepotriates in Indian valerian (Valerianajatamansi Jones.). Acta Physiologiae Plantarum. 2013; 35(1):5563.

de Souza BTJ, Ferreira AF, de Paula Rosa Ignacio AC, Albarello N. Antimicrobial activity of Anonna mucosa (Jacq.) grown in vivo and obtained by in vitroculture.Braz J Microbiol. 2015;46(3):785-789.

Ferrazzano GF, Cantile T, Roberto L, Ingenito A, Catania MR, Roscetto E, Palumbo G, Zarrelli A, Pollio A. Determination of the In vitro and In vivo Antimicrobial Activity on Salivary Streptococci and Lactobacilli and Chemical Characterization of the Phenolic Content of a Plantagolanceolata Infusion. Biomed Res Int. 2015; 1-8.

Gururaj HB, Giridhar P, Ravishankar GA. Micropropagation

of Tinosporacordifolia(Willd.) Miers ex Hook. F \&Thoms- a multipurpose medicinal plant. Cur. Sci., 2007; 92(1): 23-26.

Jain R, Sinha A, Jain D, Kachhwaha S, Kothari SL. Adevntitious shoot regeneration and in vitro biosynthesis of steroidal lactones in W. Coagulans (Stocks) Dunal Plant Cell Tissue and Organ Culture. 2011;105:135-140.

Jain SC, Pancholi B, Jain R. In-vitro Callus Propagation and Secondary Metabolite Quantification in Sericostomapauciflorum. Iran J Pharm Res. 2012; 11(4): 1103-1109.

Joladarash D, Chilkunda ND, Salimath PV. Glucose uptake-stimulatory activity of Tinosporacordifolia stem extracts in Ehrlich ascites tumor cell model system. J Food Sci Technol. 2014; 51(1): 178-182.

Karnawat M, Jain D, Singh A, Malik CP. In vitro plant regeneration from different leaf segment of Verbesinaencelioides and correlation with endogenous level of IAA. P.T.C. Biotech. 2010; 20(2): 195-201.
Kumari S, Jain P, Sharma B, Kadyan P, Dabur R. In vitro antifungal activity and probable fungicidal mechanism of aqueous extract of Barleria grandiflora. Appl. Biochem Biotechnol. 2015;175(8):3571-3584.

Mittal J, Sharma MM, Batra A. Tinosporacordifolia: a multipurpose medicinal plant- A review. J Med Plant Stud. 2014; 2(2): 32-47.

Nagarkar B, Kulkarni R, Bhondave P, Kasote D, Kulkarni O, Harsulkar A, Jagtap S. Comparative Hepatoprotective Potential of Tinosporacordifolia, Tinosporasinensis and Neem-guduchi. British J Pharma Res. 2013; 3(4): 906-916.

Patel MB, Mishra S. Hypoglycemic activity of alkaloidal fraction of Tinosporacordifolia. Phytomed. 2011; 18: 1045-1052.

Patel SS, Shah RS, Goyal RK. Anti-hyperglycemic, anti-hyperlipidemic and antioxidant effects of Dihar, a poly herbal ayurvedic formulation in streptozotocin induced diabetic rats. Ind $J$ Exp Biology. 2009; 47: 564-570.

Rao BR, Kumar DV, Amrutha RN, Jalaja N, Vaidyanath K, Rao AM, Rao S, Polavarapu R, Kishor PBK. Effect of growth regulators, carbon source and cell aggregate size on berberine production from cell cultures of Tinospora cordifolia Miers. Cur Tren Biotechnol and Pharma. 2008; 2(2): 269 -276.

Sangeethaa MK, Priya CDM, Vasanthia HR. Antidiabetic property of Tinosporacordifolia and its active compound is mediated through the expression of Glut-4 in L6 myotubes. Phytomed. 2013; 20: 246- 248.

Sen A, Sharma MM, Grover D, Batra A. In vitro regeneration of PhyllanthusamarusSchum. And Thonn: An important medicinal plant. One Nature. 2009; 7(1): 110-115.

Sharada M, Ahuja A, Suri Ka, Vij SP, Khajuria RK, Verma V, Kumar A. Withanolide production by in vitro cultures of Withaniasomnifera and its association with differentiation. Biologia Plantarum. 2007; 51(1):161-164.

Sharma MM, Dhingra M, Dave A, Batra A. Plant regeneration and stimulation of in vitro flowering in Eruca sativa Mill. Afr J Biotech. 2012; 11(31): 7906-7911.

Sharma S, Rathi N, Kamal B, Pundir D, Kaur B, Arya S. Conservation of biodiversity of highly important medicinal plants of India through tissue culture technology- a review. Agr. Biol J North Ame. 2010; 1(5): 827-833. 
Shukla S, Shukla SK. In vitro regeneration of Dioscoreahispida through nodal explants - A rich source of starch. G.S.T.F. J. BioSciences. 2014; 3(1): 30-35.

Sivakumar V, Rajan MSD, Sadiq AM, Jayanthi M. In vitroMicropropagation of Tinospora cordifolia (Willd.) Miers ex Hook. F. \&Thoms An Important Medicinal Plant. J. Pharmacog Phytochem. 2014; 3(2): 5-10.

Srivastava G, Jain R, Vyas N, Mehta A, Kachhwaha S, Kothari SL. Antimicrobial activity of the methanolic extract, fractions and isolated compounds from Citrulluscolocynthis (1.) Schrad. Int J Pharma Bio Sci. 2013; 4(3): $825-833$.

Upadhyay PR, Sharma V, Anita KV. Assessment of the multifaceted immunomodulatory potential of the aqueous extract of Tinospora cordifolia. Res J Chem Sci. 2011; 1: 71-79.

Vahid-Dastjerdi E, Sarmast Z, Abdolazimi Z, Mahboubi A, Amdjadi P, Kamalinejad M. Effect of Rhuscoriaria L. water extract on five common oral bacteria and bacterial biofilm formation on orthodontic wire. Iran $J$ Microbiol. 2014; 6(4): 269-275.
Wintola OA, Afolayan AJ. The antibacterial, phytochemicals and antioxidants evaluation of the root extracts of HydnoraafricanaThunb. used as antidysenteric in Eastern Cape Province, South Africa. BMC Complement Altern Med. 2015; 15:307.

Wright G.D. Antibiotic resistance in the environment: a link to the clinic. Curr Opin Microbiol. 2010; 13(5): 589-594.

Yue W, Ming QL, Lin B, Rahman K, Zheng CJ, Han T, Qin LP. Medicinal plant cell suspension cultures: pharmaceutical applications and highyielding strategies for the desired secondary metabolites. Crit Rev Biotechnol. 2014; 25:1-18.

Zhou L, Liang Y, Wang W, Tan H, Xiao M, Fan C, $\mathrm{Yu}$ R. Biotransformation of 4-phenylcoumarin by transgenic hairy roots of Polygonum multiflorum. J Med Plant Res. 2011;5(17): 4274-4278.

Received: August 25, 2015; Accepted: December 16, 2015. 